\title{
Cristavaren Cortesia eskuizkribuaz (XIX. m.) - Ohar Bibliografikoa \\ About the manuscript entitled "Cristavaren cortesia» (19th century) - A bibliographical note
}

Bittor Hidalgo

\begin{abstract}
In 1992 Patxi Altuna published in the ASJU journal the anonymous and until then unpublished manuscript titled Cristavaren Cortesia (Christian's Courtesy). In his work, he strongly defends the hypothesis that the manuscript must be from around the year 1750, and that the manuscript's author could be the already known writer Kardaberaz. Newly found documents show that the Courtesy manuscript is a literal translation of a document titled Urbanidad (Urbanity) first published in Spanish in 1798, and which was attached to the Torcuato Torio de la Riva and Herrero's Arte de escribir por reglas..., a widely spread book all along the next century. The unknown translator would possibly have written it between the years 1816 and 1840, and then he (or somebody else) left the manuscript in the Loyola's archive.
\end{abstract}

Keywords: Courtesy, Basque language manuscript, first half of the nineteenth century, bibliographic note.

\section{Laburpena}

Patxi Altunak 1992 an argitaratu zuen ASJU aldizkarian ordura arte argitaratu gabea zen Cristavaren Cortesia izeneko euskarazko eskuizkribu anonimoa. Bertan nabikoa indarrez hipotetizatzen da eskuizkribua 1750 ingurukoa izan ote litekeen, eta are agian Kardaberazen eskukoa. Orain aurkitu dokumentuek, berriz, erakutsiko lukete Kortesia eskuizkribua, aurretik espainolez Torcuato Torio de la Riva eta Herrero jaunak, lehenbizikoz 1798an Arte de escribir por reglas... liburu ondo zabalduaren eranskin gisa-edo argitaratuko duen Urbanitate-edo idazkiaren itzulpen literal estua dela, eta autore 'ezezagunak' sortua —eta gero Loiolako artxiboan utzia_ seguru asko 1816-1840 urteen artean.

Hitz gakoak: Kortesia, eskuizkribua, XIX. mendearen lehen erdia, ohar bibliografikoa. 
Patxi Altunak argitaratu zuen 1992an «Cortesia» izenburuko artikulua (ASJU 1992, 119-143), eta bertan bere oharrak erantsita ematen du argitara Cristavaren Cortesia izeneko eskuizkribua, garaian bere eskuetan zena, lehenik xIx. mendean barrena Loiolako josulagunen artxiboan aurkitua, geroztik aita J.I. Aranak (18381896) inoiz gainetik landu eta zuzendua, gero xx. mendean zehar aita J. Goikoetxeak noizbait berraurkitua, azkenean P. Altunaren (1927-2006) eskuetara iritsiko dena.

J. Goikoetxeak idatziak utzitako paperen artean aipatzen zuen jada eskuizkribuari xviII. mendeko itxura hartu ote zion (cf. Altuna 1992: 120). Eta J.I. Aranak ere hala moduz zioen jada, zuzentzen edo egokitzen erabili zuen eskuizkribuari erantsitako oharrean: "juan dan eunkidaren erdi-aldean itzcribatua izan bear du, uste degunez»; xviII. mende erdi aldera beraz, $\approx 1750$. Ohar horretan Aranak eskuizkribuaren egile izenik iradoki gabe ere, aipatzen du jada Kardaberazen izena garai hartako beste hainbat paperen egiletzat. Aranak nolanahi, agerian aipatzen du, beste inongo datu berririk eskaintzen ez badu ere, eskuizkribuak «Aita Agustin Kardaberazen itzulpen edo saiakera dirudiela» (cf. Altuna 1992: 122), bere lagun Agustin Jauregi Azpeitiko apaiz gerrillari Donostiako Aieten jaioari idatzitako eskutitzean, B. Etxegaraik 1930ean argitaratuko duenean (cf. Altuna 1992: 121). ${ }^{1}$ Bertan Arana euskarak irakaskuntzan izan beharreko eginkizunaren inguruan-edo ari bide da, eta eskuizkribuko Kristauaren Gizalege edo Kortesia-ren gaineko 'liburuxka' proposatzen bide du euskal ikasleen irakurketarako egoki.

Altunak artikuluan ez du Kardaberazen egiletasunik baieztatzen, baina bai onartzen hipotesi gisa. Eta bere kabutik eransten gainera hipotesi horretan, eskuizkribuaren lehen konposizio garaiak 1745 eta 1767 bitartekoa behar zuela izan. 1745 ondorengoa, eskuizkribuaren lexikoak Larramendiren 1745eko Hiztegi Hirueleduna-ren segizio arrasto nabarmenak dituelakoan. Eta 1767 aurrekoa, urte horretan atzerriratzen duelako Espainiako Karlos III.a erregeak Jesusen Konpainia Espainiako lurretatik, eta Loiolatik ere beraz, eta josulagunak ez direlako berriro Loiolara itzuliko 1816. urtea bitartean.

Geroztik ez dugu uste inor aritu denik eskuizkribuaren inguruan. OEHko erreferentzietan ere hala moduz eskaintzen da data (Mitxelena 1988-: 14): «Cortesia: Cristavaren Cortesia (s. XviII)»; nahiz uste dugun behin baino ez dela testua aipatzen —ikaslagun sarreran-.

Gaur egun ordea testuen digitaltzeari eta sare informatikoari esker askoz errazagoa da zernahi testuren arrastoa jarraitzea, eta hala aurkitu uste dugu gure Cristavaren Cortesia-ren jatorrizko espainolezko testua, zeinaren itzulpen zuzena baino ez den izango euskarazko eskuizkribua.

1798an argitaratzen da lehenengoz, Espainian, Madrilen, Torcuato Torio de la Riva eta Herrero jaunak konposatu izenburu luzeko Arte de escribir por reglas y con muestras según la doctrina de los mejores autores antiguos y modernos, extranjeros

${ }^{1}$ Agustin Jauregi (1838-?) —artikuluan aurrerago ere aipatuko dugun — apaizaren bizitzaz (eta honen euskarazko idatziez eta kalitateaz —estilista fintzat hartzen da-), ik. Uztarria.eus, non kontatzen den ere: «Azpeitian, beste altxamendu karlista bat zetorren ustean, Izarraitzera jo zuen herriko gazte askok 1870eko abuztuaren 29an. Guztien buru, azken hamabost hilabeteetan herriko erretore zen Agustin Jauregi. Armak $[\ldots]$ fabrikatik atera eta gorde izan zituen honek koro atzean, ...». 
y nacionales hezkuntza liburu sendo eta garrantzitsua. ${ }^{2}$ Liburu erdia baino gehiago (246 orr.) hartzen du idazteko arteak (kaligrafiak), baina Torio jaunak beste hainbat eranskin gehituko dio gai «nagusi» honi, eta hala jarraitzen du izenburuak: ...acompañado de unos principios de Aritmética, Gramática y Ortografía Castellana, Urbanidad y varios sistemas para la formación y enseñanza de los principales caractéres que se usan en Europa. Hain zuzen, azken atal Urbanitate honen itzulpena izango da Loiolako Cortesia eskuizkribua; Torioren 1798ko lehen argitalpenaren 397-418 bitarteko 22 orrialdeena (1802an 2. argitalpen zabalduena izango deneko 424-445 22 orrialde -ia- aldaketa gabeak).

Jatorrizkoak, itzulpenak bezala, sarrera bat du (Proemioa jatorrizkoan), eta ondoren 12 ikasgaitan, leziotan, banatuta bere giza jardunbideari buruzko irakaspena. Aise jabetuko da bat zenbateraino estu lotuak diren jatorrizko testua eta itzulpena elkarren ondoan ikusi orduko segidan bi zutabetan elkarren parean jaso ditugun Proemio (Torio 1798, 397-9) eta Sarrera (Altuna 1992: 124-6) atalak: ${ }^{3}$

Urbanidad y Cortesía del Christiano
Proemio.
La definicion que hacen los antiguos de la Urba-
nidad, diciendo que es una ciencia que enseña á
colocar en su debido lugar lo que hemos de hacer ó
decir, no se reduce á otra cosa que á la verdadera
modestia y honestidad que deben acompañar á
todas nuestras acciones y palabras; pero no pu-
diendo poseerse estas cualidades sin la inestimable
prenda de la humildad, que debe ser el funda-
mento de todas nuestras operaciones y sentimien-
tos, se infiere con claridad, que aquel será mas
político que sea mas humilde, y al contrario.

Por tanto , para que los jóvenes posean esta virtud tan útil cuanto estimable en el escrupuloso y delicado trato de la vida civil, es menester que los padres y maestros se la inculquen á sus hijos y discípulos desde la mas tierna edad.

Ella es, á diferencia de la vanidad y soberbia que vienen del amor propio, la joya apreciable, cuyo valor é interes arrastra tras sí el corazon del hombre que la observa.

\section{CRISTAVAREN CORTESIA}

\section{Sarrera}

Zarrac edo lenagocoac cortesiaren gañean eguiten deben arguitcea, esanaz dala jaquinduria bat eracusten debana ifinten bear duen lecuan esan ta eguin bear deguna, ezta bada beste gauzaric eguiazco modestia ta honestidadea baño, ceñac lagundu bear dituen gure eguiteco ta itz guciac; baña nola euqui ecin litezquean doai edo prenda oec humildadearen prenda estimagarria gabe, ceñac izan bear duen gure eguiteco ta iritcien asiera, nundic ezagutcen dan claru humildea dana izango dala cortesagoa.

Argatic bada gazteac euqui decen virtute aiń on edo egoquia nola estimagarria vicitza chatar onetaco tratu escrupuloso ta delicaduan, precisoa10 da Gurasoac ta Maisuac berriztatcea au beren Seme ta Discipuluai guztiz gaztetatic.

Virtute au da vanidade ta soberbiaren contracoa, ceñac datocen bacoitzac bere buruari dion amorio gueieguitic; joia estimagarria, ceñaren valore ta interesac daraman arrastaca bere ondoren bera gordetcen deban guizonaren viotza.

${ }^{2}$ XXVIII sarrera orrialde, gehi 418 orrialde zenbatu, gehi 58 azalpeneko marrazki zenbatu eta tartekatu, gehi zenbatu gabeko orrialde zuri hainbat: denera, 576 orrialde azal eta guzti —Google Books: http://books.google.es/; http://books.google.fr/

${ }_{3}$ Bi testuen jatorrizko lerrokada banaketa baino — berez jada guztiz bat ez datorrena- puntutik punturakoa egin dugu, beste gabe, konparaketa errazte aldera — euskarazkoan testuan ez ditugu jaso argitaratzailearen ohar ugariak-. 
No solamente consiste en pensar de sí mismo con pocas ventajas, sino en preferir siempre en las cosas lícitas la complacencia y comodidad agena á la suya propia, hasta el extremo de horrorizarse de cuanto pueda desazonar ó perjudicar al prógimo, que es en lo que consiste la verdadera modestia y humildad christiana, tan semejantes y análogas á la caridad, que insensiblemente nos encaminan á amar á nuestros semejantes, y á no hacer con ellos lo que no quisiéramos se hiciese con nosotros mismos.

A cuatro cláusulas podemos reducir la práctica de la ciencia urbana : primera , á portarse cada uno según su edad y estado: segunda á mirar siempre á la calidad de la persona con quien se trata : tercera , á observar el tiempo en que sucede : cuarta, y á considerar el lugar en que se hace.

No hay otros medios por donde pueda conocerse el hombre á sí mismo y á los demás, y observar los lugares y el tiempo, tan necesarios para que sus acciones no parezcan descorteses y extravagantes, aun cuando por otro lado sean egecutadas con la más sana intención.

Mas para esto se necesita de parte del sugeto cierto tino y sindéresis natural, que pueda sin ofuscacion distinguir la diferente cualidad de las cosas; pues sucede muchas veces que por falta de este discernimiento se toma lo falso por lo verdadero, y se hacen misterios de cosas frívolas, al paso que por otra parte se atropellan inconsideradamente las de mayor importancia.

De aquí dimana la dificultad de distinguir la cortesía de la familiaridad, cuyo conocimiento es tan importante en ciertas ocasiones, que si en unas es enteramente urbana y decente, en otras es sumamente descortés y ofensiva.
Ez dago bacarric pensatcean beregan ventaja guchirequin, baita ere lenendu edo aurreratcean gauza cillegui edo ondo diranetan besteren atseguin, ta era, bereari guciz [ikar] $a^{4}{ }^{4}$ artean progimoari garraztasunic eman edo calteric eguin deiquion gauzetan, non dagoan eguiazco modestia ta christavaren humildadea, caridadearen ain antz andi ta ichuracoac, nun sentitu edo igarri bague zucentcen gaituzten gure antcecoac amatcera ta ez eguitera oequin gurequin eguitea naico ezguenduqueanic.

Lau partetara eracarri dezaquegu Jaquinduria cortesaren equiera; lenengoa portatcera bacoitza bere edade ta estaduaz conforme; bigarrena, beguiratcea beti tratatcen dan personaren condicioari; irugarrena, gordetcea dempora, ceñean guertatcen dan; laugarrena, consideratcea cein lecutan eguiten dan.

Eztago beste bideric, nundic ezagutu dezaquean guizonac bere burua ta besteac, ta nundic gorde toqui ta dempora ain bearrac, bere accio ta eguiteac descortesac ta zucenac-ez ez dirala vste ez dedin, beste aldetic intencioric onenarequin eguińac izanagatic ere.

Baña onetaraco bear da bacoitzaren partetic sen ciertu ta cintzo natural bat, ceñac illuntasun gabe ezagutu dezaquean gauzac nolacoac diran; bada ascotan guertatcen da erabaquitce onen faltagatic artcea falsoa eguiazcotzat ta eguiten dira gauza vts batzu misterio batzuec, beste aldetic arreta bague tropellatcen diranean importancia andico gauzac.

Emendic dator dificultade edo nequea ezagutzeco cortesia adisquidetasunagandic, ceña ezagutcea dan importancia ain andicoa ocasio batzuetan; ecen batzuetan bada ere cortes ta decentea, beste batzuetan da guztiz descortes ta ofendigarria.

${ }^{4}$ Guk asmatua da [ikar]atu-ren [ikar] hori, P. Altunaren uneko oharra jarraikiz, baina orain jatorrizko horrorizarse-ren bistara. Altunak berak guciz... atu dakar, eta oharrean eransten: «oso pasarte iluna, guztiz irakurgaitza, erabat aldatua eta zirriborroz betea baitago; gainekoa aise irakurtzen da, azpikoak ematen ditu lanak. Nabari hauxe dago: berea oso ucaturic. Oso-ren azpian guciz datza. Berea-renean bereari egon zitekeen. Ucaturic delakoak -ric B-k [aita Aranaz besteko zuzentzaileak] erantsia du eta ondoko hitza (artean) ezabatua dago. Baina zer datza ucatu-ren pean? Venzatu, agian.» 
Todo cuanto se trata en el mundo es, ó entre personas que tienen mucho conocimiento entre sí, ó entre las que tienen poco, ó entre las que no tienen ninguno.

Unas y otras tienen sus conversaciones recíprocas, ó bien de igual á igual, ó de inferior á superior, ó de superior á inferior.

Si de igual á igual hay mucho conocimiento, entónces la familiaridad es decente: si hay poco es una descortesía ; y si ninguno una ligereza de entendimiento.

Si entre inferior y superior es mucho ó poco el conocimiento que hay, es desvergüenza la llaneza ó familiaridad (a no consistir en un mandato expreso) ; pero pasa á ser insolencia y brutalidad, si absolutamente no se conocen ni tratan.

Por último, es siempre decente de superior á inferior la familiaridad, porque con ella se obliga mas al que la recibe.

Según estas circunstancias, ó son todas nuestras acciones respecto de otros absolutas é independientes, ó dependientes y no absolutas, conforme á las diferentes clases de personas superiores, iguales ó inferiores.

A las primeras casi todo las es permitido, porque mandan ; á las segundas muchas cosas , porque no hay derecho para censurarlas, y á las terceras, ninguna, porque solo las es decente lo que se encierra dentro de los límites de la modestia.

De aquí es, que la familiaridad solo corresponde á las dos primeras clases de personas, y no á la última sin órden expresa de aquellas de quienes depende, en cuyo caso debe ser, no obstante, con las precauciones correspondientes.

Como estos principios generales son muy apropósito para cualquiera que sepa aplicarlos á todas sus acciones, conviene reducirlos á reglas que expliquen por menor el modo de comportamos con los demas hombres.
Munduan tratatcen dan guztia da edo araco persona aen artean, ceinzuec deben beren artean ezagüera andi bat, edo ezagüera guchi debenen artean edo batere ezagueraric ez debenen artean.

Batzuec ta besteac dituzte eren arteco izquetac, edo dala igualetic igualera edo chiquitic andira edo anditic chiquira.

Baldin igualetic igualera badago ezagüera asco, orduan adisquidetasuna da ona; baldin ezagüera guchi badago da descortesia bat, ta batere ezpadago, da entendimentuco arintasun bat.

Baldin andiarequin chiquiaren artean dagoan ezagüera bada asco edo guchi, da lotsagabetasuna berdintasun edo adisquidetasuna (baldin ezpadago aguinte claru baten); baña pasatcen da izatera lotsagabequeria ta ganaduqueria, baldin osoro ezagutcen ta tratatcen ezpadira.

Azquenic beti da decentea anditic chiquiraco adisquidetasuna, cergatic arequin obligatcen dan gueiago vra artcen debana.

Darraicon oez conforme gure accio guztiac dira besteai beguiraturic esequigabecoac edo esequiac ta ez osoac persona andiagoen, igualen edo chiquiagoen diferenciaz conforme.

Lenengoai, ceñac diran andiagoac, casic guztia uzten zaiete aguintea dauquelaco; bigarrengoai, ceñac diran igualac, gauza asco, cergatic ez dagoan vide zucenic aec murmuratzeco; irugarrengoai, ceñac diran chiquiagoac, ez zate vzten batere, cerren oenzat dan decente bacarric modestiaren muga barruan dagoan vra.

Emendic da adisquidetasuna ta alcarraquico tratatcea dagoquiela bacarric lenengo persona mueta biai, ta ez azquenecoari, aguincen dionaren ordena aguiri bague; orduan ere izan bear du dagoquien beguira-vneaquin.

Nola aciera guztiraco oec diran guciz egoquiac bere accio edo eguindeai aplicatcen daquian edoceńentzat, combeni da parteca esplicatcea gu beste guizonaquin portatceco modua. 
Leidas y releidas en las escuelas por los jóvenes que á ellas acuden , adquirirán el debido conocimiento de la ciencia cortés y urbana, y tendrán con él un norte seguro por donde dirigirse en todas sus operaciones al bien obrar, y proporcionarse insensiblemente la llave maestra con que, cómo digimos en la introducción, se abren las puertas del templo de la fortuna. ${ }^{5}$
Iracurri ta berriztaturic escoletara juaten diran mutil gazteac artuco debe bear dan ezagüera jaquinduria cortesarena, ta eduquico debe berarequin argui-izar seguru bat beren eguiteco guztiac ondo eguiteco ta gaitzeco igarri gabe guilza maisua, ceñarequin, sarreran esan guenduan becela, iriquitcen diran demporaco fortunaren ateac.

Ez da zalantza handirik bi testuon arteko lotura ezin estuagoaz, eta halaxe jarraitzen dute biek ondoko 12 ikasgaietan ere, jada iragarri litekeen moduan 'lezioen' izenburuak parekatuz:

\begin{tabular}{|c|c|}
\hline Leccion Primera. Del culto divino. & $\begin{array}{l}\text { LENENGO LECIOA - Jaungoicoari bear zaion ado- } \\
\text { racioaren gañean. }\end{array}$ \\
\hline $\begin{array}{l}\text { LeCcion II. Del respeto que se debe tener á los pa- } \\
\text { dres, maestros y mayores. }\end{array}$ & $\begin{array}{l}\text { BIGARREN IRACURRALDIA }{ }^{6} \text { - Guraso, Maisu eta beste } \\
\text { mallaz goragocoaquin nola tratatu bear.dan. }\end{array}$ \\
\hline $\begin{array}{l}\text { LeCcion III. Del trato de los inferiores con los su- } \\
\text { periores. }\end{array}$ & $\begin{array}{l}\text { IRUGARREN LECIOA - Nola tratatu bear deben } \\
\text { chiquiac andiaquin. }\end{array}$ \\
\hline $\begin{array}{l}\text { LeCcion IV. Del trato de los superiores con los in- } \\
\quad \text { feriores. }\end{array}$ & $\begin{array}{l}\text { LAUGARREN LECIOA -Andiac chiquiaquln nola } \\
\text { tratatu bear deben. }\end{array}$ \\
\hline LeCCION V. Del trato entre personas iguales. & $\begin{array}{l}\text { BOSTGARREN LECIOA - Igualen arteco tratuaren } \\
\text { gańean. }\end{array}$ \\
\hline LeCcion VI. De la limpieza y aseo. & $\begin{array}{l}\text { SEIGARREN LECIOA - Garbitasunaren, ta apain- } \\
\text { tcearen gañean. }\end{array}$ \\
\hline $\begin{array}{l}\text { Leccion VII. De la modestia y compostura en la } \\
\quad \text { escuela. }\end{array}$ & $\begin{array}{l}\text { ZAZPIGARREN LECIOA - Escolaco modestia, ta } \\
\text { posturaren gañean. }\end{array}$ \\
\hline LeCCION VIII. De la conversación. & ZORCIGARREN LECIOA - Conversacioaren gañean. \\
\hline $\begin{array}{l}\text { Leccion IX. De lo que se debe observar en la } \\
\text { mesa. }\end{array}$ & $\begin{array}{l}\text { BEDERATCIGARREN LECIOA - Maian eduqui bear } \\
\text { dan cuidadoaren gañean. }\end{array}$ \\
\hline Leccion X. Del paseo. & AMARGARREN LeCiOA - Paseoaren gañean. \\
\hline Leccion XI. De la diversión. & AMAiCAGARREN LECIOA - Diversioaren gañean. \\
\hline $\begin{array}{l}\text { LECCION XII. La decencia general consiste en con- } \\
\text { formarse con las circunstancias de persona, lu- } \\
\text { gar y tiempo. }\end{array}$ & $\begin{array}{l}\text { AMABIGARREN LeCiOA - Guztiraco ona dana da, } \\
\text { conformatcea persona, lecu, ta demboraren } \\
\text { circunstanciaquin. }\end{array}$ \\
\hline
\end{tabular}

5 Espainolezko Proemio-ak badu oraindik beste azken lerrokada bat euskarazkoak ez duena, ondoren jasoko duguna aipatzen dituen datuak direla eta.

6 Bigarren 'lezio' / 'irakurraldi' honen izenburua —eta eskuizkribuaren orrialde hori osoa nonbaitJ.I. Aranaren berridazketa bide da osorik (cf. Altuna 1996: 122). 


\section{Noizkoa da orduan euskarazko eskuizkribua?}

Behin euskarazko Kortesia eskuizkribu honen 'jaiopidea' sumatuta, ezin jada onartu XVIII. mende erdi inguruko jaiotza datarik. Gutxienez 1798 ondokoa behar du izan. Ongi ziurtatzen saiatu gara Torio-ren liburu honen lehen argitalpena data horretan dela, eta bere beste liburuetan ez dela urbanitateari buruzko halakorik barne. ${ }^{7}$ Eta eskuizkribua seguruenik izango da $1802 \mathrm{z}$ ondorengoa ere, dirudienez 1798ko lehen argitalpena hainbat mugatua eta zabalpen handiegirik gabekoa izan zelako (cf. Torio 1802: v), eta aldiz 1802ko argitalpena bai pentsatua ikaragarri zabaltzeko Espainia guzti(et)ako eskola, hezkuntza sistemetan barrena, bere garaian ere ondo aitortutako orokortasun, berritasun eta egokitasun, are pedagogikoen, karietara, eta arrakasta handia ezagutuko du penintsulako Espaini(et)an, zein garaian Espainiaren kolonia ziren Amerika eta abarretako herrialdeetan.

Eta izan ere Torio jauna ez bide zen edozein jada lehen argitalpenaren garairako ere. Hala dio bere bi argitalpenon barne azaleko argibideetan izenburu luzearen ondotik bere burua aurkezteko: Compuesto Por Don Torquato Torio de la Riva y Herrero, Socio de número de la Real Sociedad económica Matritense; Oficial del Archivo del Excelentísimo Señor Marques de Astorga, Conde de Altamira; Escritor de Privilegios, y Revisor de Letras antiguas por S. $M$.

$1802 \mathrm{ko} \mathrm{bigarren} \mathrm{edizioak}^{8}$ sarrerako orrialdeen artean erantsia du halako 'Privilegio' bat, garaiko Espainiako errege Karlos IV.enaren aurreko urteko, 1801 eko, urtarrileko agindua barne duela, azalduaz honek, batetik, liburuaren egokitasuna, eta lehen argitalpenaren mugak, eta aginduaz bestetik, indar guztiz egin dadin liburuaren 2. argitalpena, eta zabaldu lehenbailehen Espainia guztiko eskoletara eta hezkuntzara. Hala dio erregearen 'Pribilegioak' (Torio 1802, V): comunicó al escelentísimo señor gobernador del Consejo [del Reino(?)] con fecha de 31 de enero de 1801 la real orden siguiente: "Enterado el Rey del celo, singular inteligencia y aplicación con que don Torquato Torio de la Riva en beneficio de la primera educacion ha impreso á costa de su propio haber con considerables desembolsos la obra que compuso intitulada Arte de escribir por reglas y con muestras \& $^{*}$ c. $y$ asimismo de la utilidad y adelantamientos que de la observancia del método que establece en todas sus partes se ha esperimentado en el real seminario de Nobles de esta corte y en otros establecimientos dedicados á la primera enseñanza; á fin de que ésta se logre generalmente observándose el sistema de Torio, se ha servido S.M. de mandar, que se distribuyan egemplares de su obra á todas las escuelas de las ciudades, villas y lugares del reyno, pagándose de sus respectivos propios y arbitrios; y también á todas las sociedades económicas, universidades literarias, seminarios, academias, colegios y demás cuerpos y comunidades á cuyo cargo esté la primera educación de la juventud, pagándose igualmente de sus fondos. Lo que de real órden comunico á V.E. para su inteligencia, y que espida cuantas sean necesarias y correspondientes al cumplimiento de esta real determinacion."

7 Torio-ren biografiaz eta bereziki liburu honen garaiko garrantziaz jabetzeko ikusi litezke Galende (1993), Imparato-Prieur, S. (2000).

8 Eta bitxi, itxuraz 1798ko 'lehen edizioko' zenbait alek ere bai, nola Google Books [Liburuak]: http://books.google.es/ - http://books.google.fr/-en doan eskuratu litekeen 1798ko 'I.N.L.E. Delegación de Barcelona' bateko alea, orainago Biblioteca de Catalunya-n jasoa dirudienez. 
Gure kasuan gainera aipagarria da delako pribilegio-aren jarraipena, bertan espres aipatzen diren neurrian Bizkaia, Gipuzkoa eta Arabako aginteak agindua betetze aldera (Torio 1802: v):

Esta real orden la pasó al Consejo el señor gobernador; y en su cumplimiento, y teniendo presente lo espuesto por los señores fiscales, acordó en resolución de 23 de marzo del mismo ańo, que los intendentes del reyno y los corregidores del señorío de Vizcaya, provincia de Guipúzcoa y diputado general de la de Âlava , con la posible brevedad, y tomando las noticias que estimasen conducentes, informasen el número fijo de escuelas de primeras letras que hubiese en cada uno de los pueblos de sus respectivas provincias, espresando las que se sostuviesen á costa de los propios de cada pueblo , y las pertenecientes á las sociedades económicas, universidades literarias, seminarios, academias, colegios y demás cuerpos y comunidades á cuyo cargo estuviese la primera educación de la juventud.

Eta balirudike asmoa behintzat zorrotz betetzea izan zela delako 'erretagindua', 'pribilegioak' jarraitzen duen tenorearen bistara.'

Ezagutzen ditugun Torioren liburuaren beste ale eta xIx. mendeko erreferentzia (ia) guztiak dira $1802 \mathrm{ko}$ argitalpenari dagozkionak (edo honen izenekoak). ${ }^{10}$ Eta soilik beste hirugarren argitalpen baten berri dugu jada 1903. urtean (Google Books [Liburuak]).

Torio jaunak nolanahi euskarazko eskuizkribuaren sarrerak itzultzen ez duen proemio-aren azken lerrokadan zuzen aitortzen ditu bere iturriak, edo hauetako batzuk behintzat (Torio 1798: 399; 1802: 426):

9 Torio 1802, V-VI: Habiéndose despachado la correspondiente circular á los intendentes del reyno, y evacuado por algunos de ellos sus informes en el siguiente mes de abril, se sirvió el Consejo mandar, entre otras cosas, que asi éstos como los demás intendentes, á proporción de como fuesen cumpliendo con el tenor de la referida circular, se pongan de acuerdo con el citado don Torquato ó su apoderado, y dirijan la orden correspondiente con insercion de la de S.M. á las justicias de los pueblos de sus respectivas provincias, previniéndolas que en puntual cumplimiento de la citada real orden diputen persona que á su nombre, y en el término y sitio que señalen, acuda á recibir un egemplar de esta obra para cada escuela, satisfaciendo su importe por parte del pueblo y por cuenta de los cuidales de sus propios, recogiendo el recibo correspondiente de dicho Torio, ó de quien le represente, para que sirva de abono, y encargando á las justicias que el referido egemplar le entreguen al maestro de la escuela bajo de recibo, y la obligación de responder de él $y$ de seguir su método, con lo demás que estimen correspondiente á la egecución de lo resuelto por $S$. $M$., copiándose en el libro de acuerdos del ayuntamiento la orden que circulen dichos intendentes para que siempre conste, y pueda hacerse cargo al maestro de la responsabilidad de este libro, y de si observa ó no el método y reglas que en él se establecen. Que del mismo modo pasen dichos intendentes las correspondientes órdenes á las personas que hagan cabeza de las sociedades económicas, universidades literarias, academias, colegios, hospicios, casas de misericordia y demás cuerpos y comunidades á cuyo cargo estuviere la primera educación de la juventud, para que dispongan se acuda á recibir los respectivos egemplares de esta obra y satisfacer su importe de sus respectivos fondos, bajo el correspondiente resguardo; previniendo el Consejo á los intendentes que para que se verifique la entrega de los egemplares en cada escuela, la satisfacción de su importe, y el que en cada una se observe su método, acuerden las providencias mas oportunas, y den cuenta al Consejo mensualmente de las escuelas que fuesen poniendo en uso este Arte, prestando al don Torquato Torio ó sus apoderados los ausilios que les pidieren y necesiten para la egecucion de lo mandado por S. M. en la citada real orden.

${ }_{10}$ Nolanahi Gasteizko Sancho El Sabio fundazioak badu nonbait Bilbon argitaraturiko 'beste 2. edizio' bat ere eta zalantzan bada ere 1806 urtea ematen dio: «Impresa en Bilbao: por Francisco de San -Martín, Segunda edicion [1806?]». 
Las obras de que principalmente nos hemos valido para componer las cortas lecciones que ofrecemos al público, son la Urbanidad y cortesía universal, traducida del Francés por Don Ignacio Benito Avalle, y los Elementos de Gramática Castellana, Ortografia, Calografia [sic] y Urbanidad, dispuestos para uso de los discipulos de las Escuelas Pias por el PADRE SANTIAGO DELGADO, Sacerdote de las mismas. Uno y otro autor escribieron con tanto acierto y tan arreglados al fin que respectivamente se propusieron (muy conforme al mio), que he tenido por conveniente tomarlos por modelo, y no callar en este lugar lo mucho á que les soy deudor.

Propio haztatzen ibili gara liburu hauetakoren bat (ere) izan ote litekeen euskarazko eskuizkribuaren iturri ere, baina ez dirudi kasua. Avalle jaunak frantsesetik itzultzen duen liburua (ap. Google Books [Liburuak]) 1744an argitaratzen da lehenbizikoz espainolez, 1762an du 2. argitalpena, eta badugu 1778ko 3. baten aparteko erreferentzia bibliografikoa ere. ${ }^{11}$ Sarean ordea ezin izan dugu zuzenean batere alerik ikuskatu. Bai ordea, Avalle jaunaren frantsesezko jatorrizko iturburua den Jacques de Ca[i]llières-en Traitté de la fortune des gens de qualité et des gentilshommes particuliers liburua. $\mathrm{Ca}[\mathrm{i}]$ llières jaunak lehendabizikoz $1657 \mathrm{an}$ argitaratzen bide du bere liburua (1658an diote hala ere hainbat alek), eta 1661 ean bigarrena (izenburua aldatuxea), ${ }^{12}$ eta ondoko 10-12 urteren buruan ezagutzen ditu beste hamarren bat argitalpen gutxienez frantsesez, eta itzulpenak alemanez eta italieraz bederen. Eta gaiaren aldetik —eta batez ere espainolezko itzulpenaren izenburutik— ${ }^{13}$ antzekotasunik aurkitu badakioke ere Torioren lanarekin, ez dute biek lotura zuzenik, eta euskarazko eskuizkribuak erakusten dituen parekotasunak ere, ez dira Toriorenari darizkionak baino.

Estuagoa da Torioren 'urbanitatearen’ zerikusia Aita eskolapio Santiago Delgadoren liburuarekin, eta izango du horretan zerikusia Torio jaunaren garaiko harreman estuak eskolapioekin (Galende 1993: 501). Delgadoren liburua (ap. Google Books [Liburuak]), 1790ean argitaratzen da lehendabizikoz, 1799an bigarrenez, eta badu 3. argitalpen bat behintzat, agian egunekotua, 1833an 'berri' hitza erantsita izenburuari (Nuevos elementos...). ${ }^{14}$ Torio jaunak, zalantza gabe asko zor dio Santiago Delgadoren liburuaren azken 'urbanitate' atalari, mamian zein antolaketan, bien atalen arteko konparaketan sumatu litekeen bezala:

11 F. Aguilar Piñal, Bibliografía de autores españoles del siglo XVIII, Vol. 6, 1991, 543 or. (ap. Google Books [Liburuak]).

${ }_{12}$ La Fortune des gens de qualité, et des gentils-hommes particuliers: enseignant l'art de viure à la cour suiuant les maximes de la politique \& de la morale, Paris, Estienne Loyson, 1661. Aurkitu ditugu nolanahi honen aurretiko 1658 urtea aipatzen duten beste hainbat ale.

13 Urbanidad y cortesía universal vs Urbanidad y cortesía del Christiano.

14 Badugu 1833ko beste argitalpen baten erreferentzia ere Hegoamerikan: «Delgado de Jesús y María, Santiago (1833). Catecismo de urbanidad civil y cristiana para el uso de las escuelas con las reglas de discreción de palabras y ceremonias en todos los casos que pueden ocurrir en el trato. Van añadido el arte de conducirse en la mesa y trinchar con desembarazo todo género de viandas. Por preguntas y respuestas fáciles. Caracas: Imprenta de Fermin Romero.»

15 Bigarren 'lezio' / 'irakurraldi' izenburua —eta eskuizkribuaren orrialde hori osoa nonbaitJ.I. Aranaren berridazketa bide da (cf. Altuna 1996: 122). 


\begin{tabular}{|c|c|c|}
\hline $\begin{array}{c}\text { TraTADO DE LA URBANIDAD } \\
\text { y CORTESIA }\end{array}$ & $\begin{array}{l}\text { URBANIDAD Y CORTESIA } \\
\text { DEL CHRISTIANO }\end{array}$ & Cristavaren Cortesia \\
\hline$\left[1790^{1}, 1799^{2}, 1833^{3}\right]$ & {$\left[1798^{1}, 1802^{2}, 1903^{3}\right]$} & [18??] \\
\hline INTRODUCCION. & Proemio & SARRERA. \\
\hline $\begin{array}{l}\text { Capitulo Primero. Qué es Ur- } \\
\text { banidad. }\end{array}$ & $\begin{array}{l}\text { Leccion Primera. Del culto } \\
\text { divino. }\end{array}$ & $\begin{array}{l}\text { LENENGO LECIOA - Jaungoi- } \\
\text { coari bear zaion adoracioa- } \\
\text { ren gańean. }\end{array}$ \\
\hline Capitulo II. Del culto divino. & $\begin{array}{l}\text { LeCCION II. Del respeto que } \\
\text { se debe tener á los padres, } \\
\text { maestros y mayores. }\end{array}$ & $\begin{array}{l}\text { BIGARREN IRACURRALDIA }{ }^{15} \text { - } \\
\text { Guraso, Maisu eta beste } \\
\text { mallaz goragocoaquin nola } \\
\text { tratatu bear.dan. }\end{array}$ \\
\hline $\begin{array}{c}\text { Capitulo III. Del respeto á los } \\
\text { Padres, Maestros y Mayores. }\end{array}$ & $\begin{array}{l}\text { LECCION III. Del trato de los in- } \\
\text { feriores con los superiores. }\end{array}$ & $\begin{array}{l}\text { IRUGARREN LECIOA - Nola tra- } \\
\text { tatu bear deben chiquiac } \\
\text { andiaquin. }\end{array}$ \\
\hline $\begin{array}{l}\text { Capitulo IV. Del tratamiento } \\
\text { á los superiores. }\end{array}$ & $\begin{array}{l}\text { LecCion IV. Del trato de los su- } \\
\text { periores con los inferiores. }\end{array}$ & $\begin{array}{l}\text { LAUGARREN LECIOA - Andiac } \\
\text { chiquiaquln nola tratatu } \\
\text { bear deben. }\end{array}$ \\
\hline $\begin{array}{l}\text { Capitulo V. De la limpieza } \\
\text { y aseo. }\end{array}$ & $\begin{array}{l}\text { LeCCION V. Del trato entre per- } \\
\text { sonas iguales. }\end{array}$ & $\begin{array}{l}\text { BostgarRen LECIOA - Igualen } \\
\text { arteco tratuaren gañean. }\end{array}$ \\
\hline $\begin{array}{l}\text { Capitulo VI. De la compostura } \\
\text { en la Escuela. }\end{array}$ & $\begin{array}{l}\text { Leccion VI. De la limpieza y } \\
\text { aseo. }\end{array}$ & $\begin{array}{l}\text { SEIGARREN LECIOA - Garbita- } \\
\text { sunaren, ta apaintcearen } \\
\text { gañean. }\end{array}$ \\
\hline Capitulo VII. Reglas del hablar. & $\begin{array}{l}\text { Leccion VII. De la modestia y } \\
\text { compostura en la escuela. }\end{array}$ & $\begin{array}{l}\text { ZAZPIGARREN LECIOA - Esco- } \\
\text { laco modestia, ta postura- } \\
\text { ren gańean. }\end{array}$ \\
\hline Capitulo VIII. Del andar. & $\begin{array}{l}\text { Leccion VIII. De la conver- } \\
\text { sación. }\end{array}$ & $\begin{array}{l}\text { ZORCIGARREN LECIOA - Con- } \\
\text { versacioaren gañean. }\end{array}$ \\
\hline $\begin{array}{l}\text { Capitulo IX. Como se ha de } \\
\text { conformar con las circuns- } \\
\text { tancias de lugar, tiempo, y } \\
\text { personas. }\end{array}$ & $\begin{array}{l}\text { LeCCION IX. De lo que se debe } \\
\text { observar en la mesa. }\end{array}$ & $\begin{array}{l}\text { BEDERATCIGARREN LECIOA - } \\
\text { Maian eduqui bear dan cui- } \\
\text { dadoaren gañean. }\end{array}$ \\
\hline $\begin{array}{c}\text { Capitulo X. De las reglas de } \\
\text { Urbanidad en la Mesa. }\end{array}$ & Leccion X. Del paseo. & $\begin{array}{l}\text { AMARgarRen LECIOA - Paseoa- } \\
\text { ren gañean. }\end{array}$ \\
\hline CAPITUlo XI. De la diversión. & LECCION XI. De la diversión. & $\begin{array}{l}\text { AMAICAGARREN LECIOA - Di- } \\
\text { versioaren gañean. }\end{array}$ \\
\hline $\begin{array}{l}\text { Nota + Reglas, Que deben } \\
\text { observar los discípulos de } \\
\text { las Escuelas Pias, y cuyo } \\
\text { quebrantamiento será se- } \\
\text { veramente reprendido de } \\
\text { nuestros Maestros. }\end{array}$ & $\begin{array}{l}\text { LECCION XII. La decencia gene- } \\
\text { ral consiste en conformarse } \\
\text { con las circunstancias de per- } \\
\text { sona, lugar y tiempo. }\end{array}$ & $\begin{array}{l}\text { AMABIGARREN LECIOA - Guz- } \\
\text { tiraco ona dana da, con- } \\
\text { formatcea persona, lecu, ta } \\
\text { demboraren circunstancia- } \\
\text { quin. }\end{array}$ \\
\hline
\end{tabular}


Euskarazko eskuizkribua ere, Toriorena bezain hurbil gertatzen da Delgadorenetik, eta Torio bezain urrun ere bai, eta Delgadori ez bezala hitzez hitz lotzen zaio Toriori. Euskaratzaileak ez du zertan Delgadoren lana ezagutu, eta ezagututa ere 1790 edo 1799 ondoren jarriko gintuzke.

Hala uste dugu beraz, euskarazko eskuizkribuak derrigor behar duela izan 1798z geroztikoa, eta ziurrenera 1802 tik aurrerakoa, Torioren liburua hedatzen hasiz geroztikoa (agian Bilbon 1806an inprimatuaz geroztikoa). Ez da alderik (ia) lehen bi argitalpenen artean, biak ere Madrileko Joakin Ibarra-ren alargunaren etxekoak, eta balirudike inpresio kaxa berak erabili zirela bi inpresioetan, orrialdeketa, lerrokadak, lerroak eta hauen amaierako hitz banaketak ere beti berdin-berdin ematen baitira, nahiz sumatu dugun bien artean tartekako aldaketa ortografikoaren bat (Christiano $\rightarrow$ Cristiano; JesuChristo $\rightarrow$ Jesucristo; excusar $\rightarrow$ escusar; tilderen bat: jamás $\rightarrow$ jamas; sandéz $\rightarrow$ sandez; eta agian bestelakorik); eta desberdina da ere bi testuen amaieran ematen den OHARRA, euskarara itzuli gabea (418 eta 445 orrialdeak hurrenez hurren).

Egin liteke nolanahi hurbilketa zehatzagorik ere, P. Altunak egin ildoan (ik. gorago), Loiolako josulagunen eta hauen egoitzaren xIx. mendeko historia txikiari begira. 1767an Espainiatik deserriratuko dira Loiolako josulagunak Espainiako errege Karlos III.aren aginduz eta Erromako Aita Santu Klemente XIV.ak gainera desegin egingo du Jesusen Konpainia 1773an, eta hala jarraituko du Aita Santu Pio VII.ak 1814an ordena berrezartzen duen arte. Eta garaiko Espainiako errege Fernando VII.ak berehala eskaini zien itzultzeko aukera. Nolanahi Loiolako josulagunen itzulinguruak XIX. mendean animatuak izango dira.

I. Aranbarri eta J.L. Otamendiren 2005eko Loiolarik ez balitz liburuaren «...ez gaitezke Loiolan deskantsuban bizi» atalean erakusten den kronologiari jarraiki, josulagunak «1816an bueltatu ziren Loiolara, ia berrogeita hamar urteko erbestealdia jiratuta». Baina berriro «1820an, Madrilgo gorte liberalek ordena desegin zuten eta jesuitak sakabanatu. Loiolatik kanpora ibiliko dira 1823an itzuli arte.» Ondoren berriz, «1835ean, Espainiako gobernuak jesuitak disolbatu zituen, baina Loiola karlisten eremuan zegoenez, bertan jarraitu zuten harik eta Carlos V.aren aldekoek gerra galduta, 1840an, euren jabetzez gabetuta, alde egin behar izan zuten arte. Loiola Azpeitiko erretorearen kargu geratu zen. 1852an Loiolan dira atzera berriz jesuitak, misiolari kolegio baten ardura hartuta.» «1854an, laugarren kanporaketa gertatu zen, "biurteko progresista"-ren garaian. Jesuita pare bat gelditu omen zen kapilau lanetan. 1856an bueltatu ziren, gobernu moderatua jarri zenean agintzen.» «1868an, Isabel II.a bota zuen iraultzaren aldian, jesuitak desegin egin zituzten, hala ere, Loiolako kolegioak martxan segi zuen. Loiola beste etxe askotatik botatako jesuiten aterpe izan zen.» «1870ean, Gipuzkoako Diputatu Nagusiaren erabakiz, berriz bidali zituzten, Agustin Jauregi apaiza buru izan zuen Azkoiti-Azpeitiko altxamendu saio karlista zapuztuari laguntzeagatik, zigor gisa. 1873tik atzera, gerra betean, Loiola Gipuzkoako karlismoaren bihotz eta erromesen bilgune bihurtu zen. Lizarraga jeneralak, 1873ko abuztuan, Loiolako giltzak bueltatu zizkien jesuitei.» Azkenik «1876an, Canovas del Castilloren gobernuak zazpigarrenez bota zituen jesuitak Loiolatik, azken karlistaldian Carlos VII.a aldeztu zutelako nabarmen. 1877ko udaberrian etorri ziren bueltan batzuk, eta 1880an gainerakoak.»

Horietako zein garaitan sortu edo geratu zitekeen Loiolako artxiboan Cristavaren Cortesia eskuizkribua? 
- Ezin 1816 bitartean.

- Goizenik, 1816. urtetik aurrera, baina soilik 1820 bitartean.

- Agian errazago 1823 eta 1840 bitarteko 17 urteetan.

- Ezin ere 1840 eta 1852 bitartean, eta zail 1852 eta 1854 bitarte.

- Agian, 1856 eta 1870 bitarteko 14 urteetan.

- Ez berriro 1870 eta 1873 bitarte.

- Bai agian 1873 eta 1876 bitartean.

- Nekezago 1877 eta 1880 bitartean.

Erraza zatekeen 1816-1820 bitartean, edo askoz errazago 1823 eta 1840 bitarteko urte luzeagoetan norbaitek Loiolan euskaratu edo eraman izana eskuizkribua, artean hain urrun izango ez zelarik 1802tik zabal hedatzen saiatzen diren Torioren liburuaren oihartzuna. Agian geroago ere, garaian ez direlako artean egun batetik bestera 'zahartzen' emaitza gustagarriak. Agian, 1856 eta 1870 bitarteko 14 urtee$\tan . .$.

Badakigu ordea (Altuna 1996; 1997; Arana 2000), aita Jose Inazio Arana, eskuizkribua eskuartean darabilen aurrenekoetakoa 1854an sartzen dela lehen aldiz Loiolako etxean josulagun bihurtzeko asmoan, artean 16 urte dituela, eta bi urte egiten bertan. 1857an Espainiako Salamancan da ikasten, baina gaixotuta itzuliko da berriro Loiolara 1858an. Salamancan berriro 1858-1860 urteetan. Espainian Palentziako Karrion-en 1860-1863 bitartean. Berriro gaixo 1864-1865ean eta Loiolaratua. Eta geldi Loiolan 1866ko urtea ( 28 urte beteko dituenekoa). Eta badirudi handik aurrera, tarteka batera eta bestera mugituta ere (Zarautz, Urduña...), Loiolako etxeari eta bertako josulagunen zorteari lotuta emango dituela bere bizitzako hurrengo 30 urteak.

Pentsatu beharko hala, eskuizkribua ez zela seguru asko sortu edo Loiolara iritsiko Arana inguruan ibili zen urteetan, bestela norbaitek eman ziezaiokeelako berri zuzenagoa, eta gainera berari bereziki, eskuizkribuaren kopia, papera, idazkera... nahikoa 'zaharrak' iruditu bide zitzaizkiolako bere garairako.

Amaitzeko, eman dezakegu beraz, eskuizkribua zalantza gabe dela xIx. mendekoa, eta izan litekeela 1816-1820 bitartekoa, edo askoz errazago 1823 eta 1840 bitartekoa, eta aita Aranari nahikoa zahar iruditu jada 40 urte beranduago edo.

\section{Bibliografia aipatua}

Altuna, P., 1992, "Cortesia». ASJU, XXVI-I (1992) 119-143. http://www.ehu.es/ojs/index. $\mathrm{php} / \mathrm{ASJU} /$ article/view/8285

_, 1996, «Jose Inazio Arana jesuitaren bizitza (1838-1896) - I». www.euskaltzaindia.net/ dok/euskera/49496.pdf

_, 1997, «Jose Inazio Arana jesuitaren bizitza (1838-1896) - II». In P. Altuna (koord.) Federiko Krutwig-i omenaldia (1996) 23-47. http://dialnet.unirioja.es/servlet/articulo? codigo $=3862890$

Arana, J.I., 2000, Aita Aranaren egunaria $=$ Diario del Padre Arana $=$ Journal du Père Arana [Patxi Altunak paratua]. Bilbo, Euskaltzaindia, Iker 12. www.euskaltzaindia.net/dok/ euskera/49496.pdf

Aranbarri, I.; J.L. Otamendi, 2005, Loiolarik ez balitz. Azpeitia, Uztarria Kultur Koordinadora. http://uztarria.com/azpeitia/liburuak/09bLoiolarik_ez_balitz/11/index_html 
de Ca[i]llières, Jacques, 1657, Traitté de la fortune des gens de qualité et des gentilshommes particuliers.

- Google Books [Liburuak]: http://books.google.es/ - http://books.google.fr/: editions: DcLGHjbQsbwC [hainbat edizio] https://www.google.es/search?tbm= bks\&hl=en\&q=la+fortune+des+gens+de+qualite $\% C C \% 81+$ et + des + gentilshommes+ particuliers\&gws_rd=ssl\#hl=en\&q=editions:DcLGHjbQsbwC\&tbm=bks [hainbat edizio]

- Google Books [Liburuak]: http://books.google.es/ - http://books.google.fr/ : editions:J1I_ nTmZkNwC [hainbat edizio] https://www.google.es/search?tbm=bks\&hl=en\&q=la+ fortune+des+gens+de+qualite $\%$ CC $\% 81+$ et+des+gentilshommes+particuliers\&gws rd=ssl\#hl=en\&q=editions:J1I_nTmZkNwC\&tbm=bks [hainbat edizio]

- Google Books [Liburuak]: http://books.google.es/ - http://books.google.fr/ : editions: CNnxynQ3TXoC [hainbat edizio] https://www.google.es/search?tbm=bks\&hl=en\&q= la+fortune+des+gens+de+qualite\%CC\% $81+$ et+des+gentilshommes+particuliers\&gws_ rd=ssl\#hl=en\&q=editions:CNnxynQ3TXoC\&tbm=bks [hainbat edizio].

de Ca[i]llières, J.; Ignacio Benito Avalle, $1744^{1}$ [1762 2 ; 17783], Urbanidad y cortesía universal, traducida del Francés por Don Ignacio Benito Avalle.

- Google Books [Liburuak]: http://books.google.es/ - http://books.google.fr/ : editions: PO4srTWjcH8C [hainbat edizio] https://www.google.es/search?tbm=bks\&hl=en\&q= la+fortune+des+gens+de+qualite $\%$ CC\% $81+$ et+des+gentilshommes+particuliers\&gws rd=ssl\#hl=en\&q=editions:PO4srTWjcH8C\&tbm=bks [hainbat edizio]

Delgado, Santiago $1790^{1}$ [17992; 1833³], Elementos de Gramática Castellana, Ortografía, Calografía [sic] y Urbanidad, dispuestos para uso de los discipulos de las Escuelas Pias por el Padre Santiago Delgado, Sacerdote de las mismas.

- Google Books [Liburuak]: http://books.google.es/ - http://books.google.fr/ : editions: U2-usrMaVkEC [hainbat edizio] https://www.google.es/search?tbm=bks\&hl=en\&q= la+fortune+des+gens+de+qualite $\%$ CC $\% 81+$ et + des+gentilshommes+particuliers \&gws_rd=ssl\#hl=en\&q=editions:U2-usrMaVkEC\&tbm=bks [hainbat edizio]

Galende, J.C., 1993, «El calígrafo Torcuato Torio de la Riva: una faceta de su vida profesional». Publicaciones de la Institución Tello Téllez de Meneses, 64 (1993) 497-516. http://dialnet.unirioja.es/descarga/articulo/2486539.pdf

Imparato-Prieur, S., 2000, «La enseñanza de las primeras letras en España en la segunda mitad del siglo xviII: contenidos y métodos a través de algunos tratados de enseñanza». Contextos Educativos 3 (2000) 235-252. http://dialnet.unirioja.es/descarga/ articulo/201061.pdf

Mitxelena, K., 1988- [2013³], «Orotariko Euskal Hiztegia - Referencias Bibliográficas», 14. or. http://euskaltzaindia.net/dok/oeh/ReferenciasBibliograficas.pdf

Torio de la Riva eta Herrero, Torkuato, $1798^{1}\left[1802^{2}\right]$, Arte de escribir por reglas y con muestras, segun la doctrina de los mejores autores antiguos y modernos, extrangeros y nacionales: acompañado de unos principios de Aritmética, Gramática y Ortografia Castellana, Urbanidad y varios sistemas para la formación y enseñanza de los principales caractéres que se usan en Europa / Compuesto Por Don Torquato Torío de la Riva y Herrero, Socio de número de la Real Sociedad económica Matritense ; Oficial del Archivo del Excelentísimo Señor Marques de Astorga, Conde de Altamira; Escritor de Privilegios, y Revisor de Letras antiguas por S. M. I Madrid MDCCXCVIIII [MDCCCII']. I En la imprenta de la Viuda de Don Joaquin Ibarra / Con las licencias necesarias. http://www.memoriadigitalvasca.es/handle/ 
10357/1928 [1798 ${ }^{1}$ [Sancho El Sabio fundazioan digitalizatua] http://www.liburuklik. euskadi.net/handle/10771/8392 [1802²] [Eusko Legebiltzarreko Liburutegian digitalizatua]

- Google Books [Liburuak]: http://books.google.es/ - http://books.google.fr/: editions: - GQKZGTAUH8C https://www.google.es/search?sa=G\&tbm=bks\&q= editions:-GQKZGTAUH8C\&ei=blD2U9q4D MHuyQPxtYL4Aw \& ved=0CCUQmBYwAA\&biw=856\&bih=1086\&dpr=1 [hainbat edizio]

- Google Books [Liburuak]: http://books.google.es/ - http://books.google.fr/: editions: vjyslwWhdKYC https://www.google.es/search?start=10\&sa= N\&tbm=bks\&q=editions:vjyslwWhdKYC\&ei=81D2U57ALKKhyAOSnILgBA\&ved=0CCQQmBYwADgK\&biw=856\&bih=1086\&dpr=1 [hainbat edizio]*

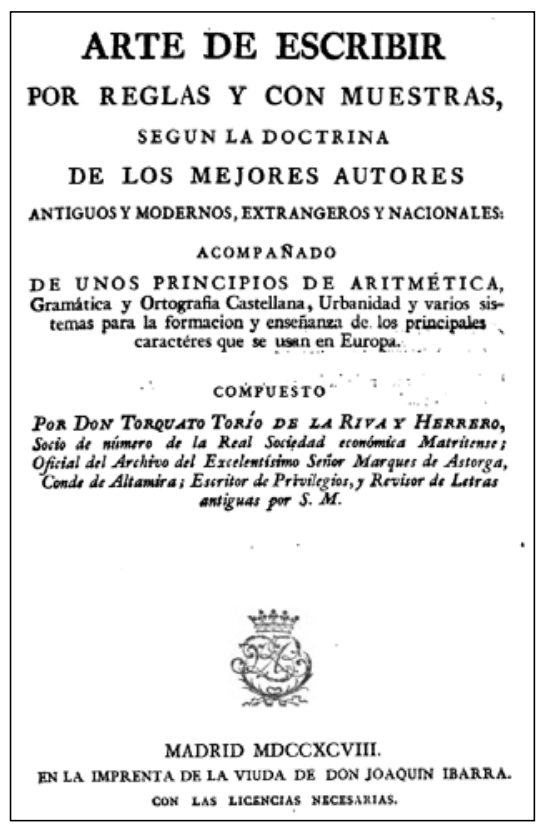

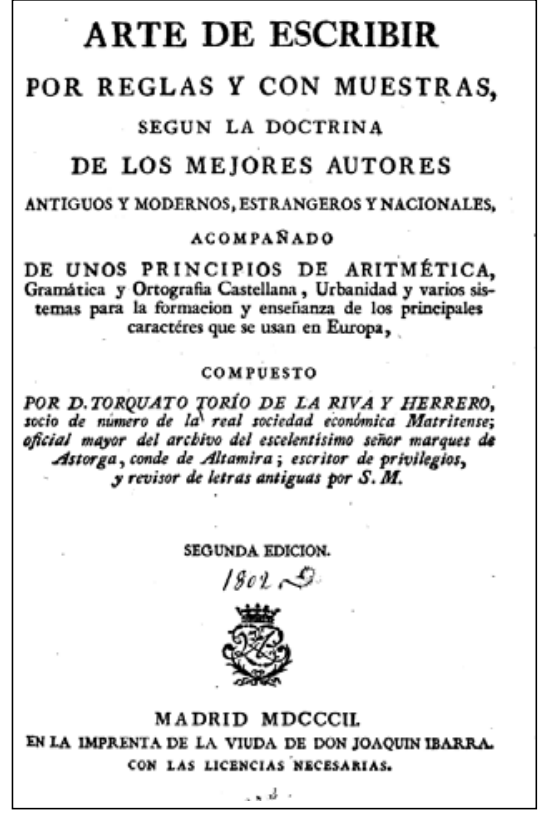

Bittor Hidalgo

bittorhidalgo@euskalnet.net

* [Argitaratzailearen Oharra: Lan hau argitaratzeko punttuan zelarik, inprenta-lanak aspaldi amaiturik, jakin dugu testu berari buruzko beste baten berri: Esteban Ochoa de Eribe, Javier, "Cristavaren Cortesia. Las fuentes hispánicas de un manual de urbanidad en euskera», Investigaciones Históricas, época moderna y contemporánea, 37 (2017), 271-295. Bertan ere CC-ren iturriarekiko ondorioa berdina da.] 